\title{
European Standardisation Process
}

\author{
Outline of presentation concerning the CEN/ISSS \\ workshop on e-skills
}

\author{
Noel Geoffrey McMullen ${ }^{1}$, John O'Sullivan ${ }^{2}$ \\ ${ }^{1}$ CEPIS Past President, Chairman CEN/ISSS ICT Skills Workshop \\ ${ }^{2}$ Consultant for CEN/ISSS ICT Skills Workshop
}

The CEN/ISSS workshop on e-skills was established in 2003 and exists to deliver CEN Workshop Agreements (CWAs) in its area of interest. The workshop has moved from general reviews of the field to the development of specific frameworks. It is now likely that the workshop will have a long life delivering CWAs embodying consensual expert opinions as precursors to full standards in this growing field.

Geoff will review the history of the workshop, its deliverables to date and the current projects, as well as work planned for 2009/10. He will cover the range of participants and the historical knowledge they bring to the workshop deliberations. He will also describe briefly the network of other active participants in this field in Europe.

He will then hand over to John O'Sullivan who will speak about the CEN/ISSS Workshop Agreement on ICT Certification.

John will start by reviewing previous work in this field, in particular the recent CEPIS project HARMONISE which reported at the end of last year. He will present updated data on that project's four main themes:

- Labour market for professional e-skills

- e-Skills certification processes

- Market for e-skills certification

- Quality standards

HARMONISE concluded that the present situation of many overlapping qualifications was a "certification jungle", with poor information, lack of 
clarity, confusing to prospective candidates and employers, to the detriment of the labour market.

He will go on to present a current follow-on project under the CEN/ISSS Workshop Agreement (CWA). This project aims to:

- Provide updated metrics on the current state of play of the main certifications in the major markets in Europe, with a methodology for annual updates

- A methodology for mapping e-certifications onto the emerging eCompetence Framework and European Qualifications Framework, with one or two worked examples

- A proposed European standard or reference model for e-certifications

By working with the main stakeholders in the field, it is hoped that industry, users and academia will welcome the new standard, and that current vendor and independent certification schemes will converge towards it. 